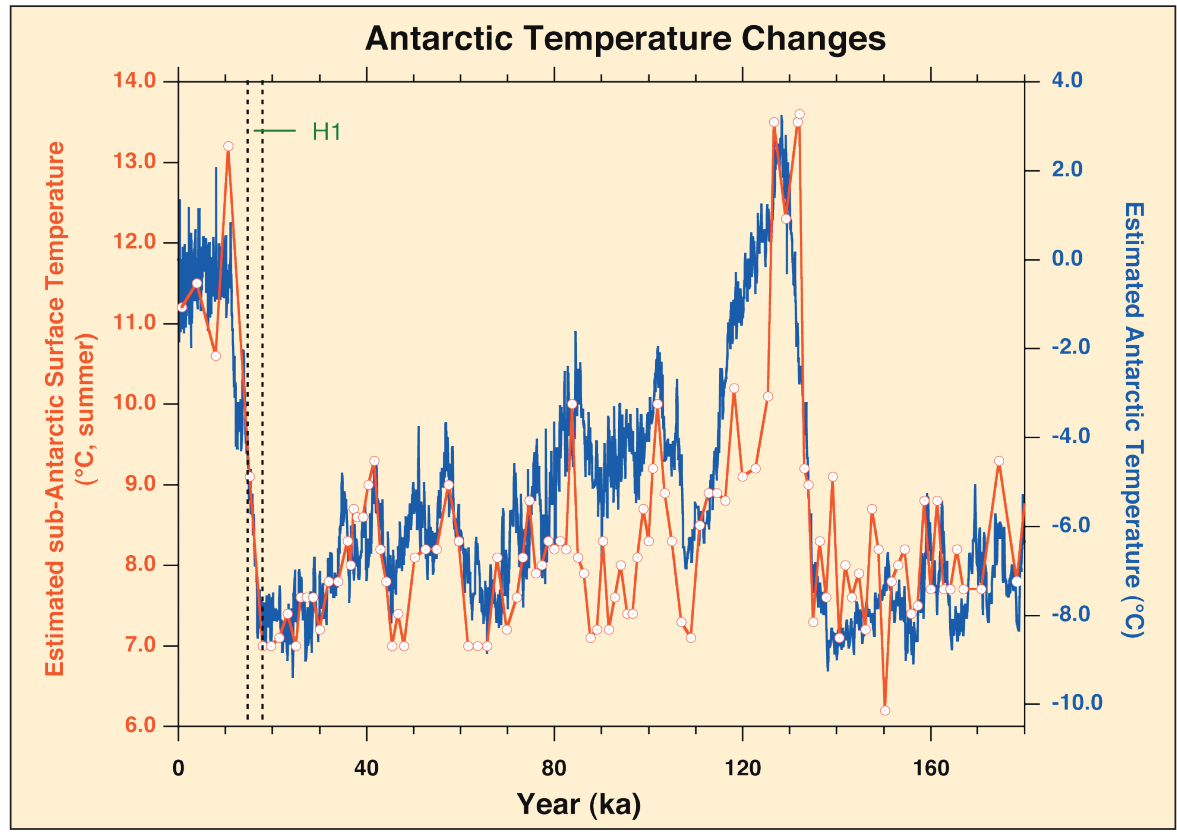

Figure 2: Comparison of the sub-Antarctic record (core RC11-120; Hays et al., 1976), using higher-resolution sampling from Martinson et al. (1987) and converted to an updated marine chronology (Lisiecki and Raymo, 2005), with the Vostok deuterium isotope record and ice core GT4 chronology (Petit et al., 1999). H1 interval is Heinrich Event 1.

this barrier after a few hundred years; R.-X. Huang, pers. comm.).

It therefore appears that the Brazil/ Malvinas-Falkland Convergence (where the southerly vectors of the Brazil Current merge with the easterly flow of the Subantarctic in Figure 1B) may be the pressure point where the heat accumulated in response to stalled Atlantic overturning circulation is injected into southern high latitudes, thereby driving the planet into deglaciation through positive feedbacks from ocean-circulation releasing carbon stored in the deep ocean around Antarc- titioning of the heat between the ocean and the atmosphere (Seager et al., 2002).

Even though the model results invoked herein represent an uncoupled run from twenty years ago, I suggest that the system response is so constrained by conservation of volume arguments-overturning shutdown in the north blocking heat export from the South Atlantic-that newer model simulations are likely to respond in the same manner. Elements of this argument can even be traced back to (or at least anticipated in) Henry Stommel's classic explanation for differences in strength of the Gulf Stream and Brazil Current (Stommel, 1965). His interpretation was certainly supported by the 1990 simulation (Maier-Reimer et al., 1990).

\section{Data}

Data for Fig. 2 from Martinson et al. (1986) and NOAA/NGDC Paleoclimatology website.

\section{References}

Crowley, T.J., 1992: North Atlantic Deep Water cools the Southern Hemisphere, Paleoceanography, 7: 489-497.

Maier-Reimer, E., Mikolajewicz, U. and Crowley, T., 1990: Ocean GCM sensitivity experiment with an open Central American Isthmus, Paleoceanography, 5: 349-366.

Negre, C., Zahn, R., Thomas, A.L., Masque, P., Henderson, G.M., Martinez-Mendez, G., Hall, A.R. and Mas, J.L., 2010: Reversed flow of Atlantic deep water during the last glacial maximum, Nature, 468: $85-88$

Rose, K.A., Sikes, E.L., Guilderson, T.P., Shane, P., Hill, T.M., Zahn, R. and Spero, H.J., 2010: Upper-ocean-to-atmosphere radiocarbon offsets imply fast deglacial carbon dioxide release, Nature, 466 : 1093-1097.

Toggweiler, J.R. and Lea, D.W., 2009: Temperature differences between the hemispheres and ice age climate variability, Paleoceanography, 25: doi:10.1029/2009PA001758.

ascinating insight into the time-space evolution of the heat package injected into the sub-Antarctic region and the par-

\title{
Paleoclimate Reconstruction Challenge: Available for participation
}

Nicholas Graham ${ }^{1}$ and Eugene WahL ${ }^{2}$

${ }^{1}$ Hydrologic Research Center, and Scripps Institution of Oceanography, USA; ngraham@hrc-lab.org 2NOAA, National Climatic Data Center, Paleoclimatology Branch/World Data Center for Paleoclimatology, Boulder, USA

The last millennia Paleoclimate Reconstruction (PR) Challenge is a model-based venue for experimenting with climate reconstruction methods. The overall idea has been described before (Ammann, 2008) and a modified version of the Challenge is now "live" and available for participation. It is designed to engage the scientific paleoclimate community in examining its methods in a common framework for the purpose of evaluating their relative strengths and weaknesses. A key design element of the Challenge is to allow true "apples to apples" comparison of reconstruction methods across identical experimental platforms. The ultimate goal is to improve last two millennia PR meth- ods so that paleoclimate science can offer the best possible information to help understand both natural and anthropogenic climate change.

The Challenge is organized around 4 themes. In each theme, a set of long $(1,000+$ yrs $)$ forced global climate model (GCM) integrations is used to formulate simulated paleoclimate proxy data (pseudo-proxies) and to provide pseudo-instrumental climate data for calibration and examination of reconstruction fidelity. Several different GCM runs provide a range of simulated climate evolutions that present different reconstruction scenarios. In each Theme, the reconstruction method used is at the prerogative of the participants.

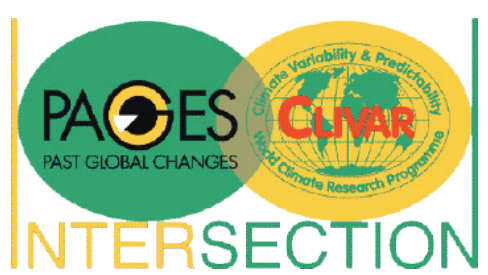

Theme 1: Reconstruction of Northern Hemisphere temperature with strongly limited proxy data set (implemented)

This theme focuses on the capacity of a very limited set of proxy data sites to enable reconstruction of hemispheric (20-90 $\mathrm{N})$ mean annual temperature. The pseudoproxy data-set consists of 14 extratropical tree-ring-chronology sites in the Northern Hemisphere (Fig. 1). It is designed to mimic the dataset used by Esper et al. (2002).

Theme 2: Reconstruction of Northern Hemisphere temperature and spatial patterns with a richer, but still somewhat limited proxy data set (in process of implementation) 


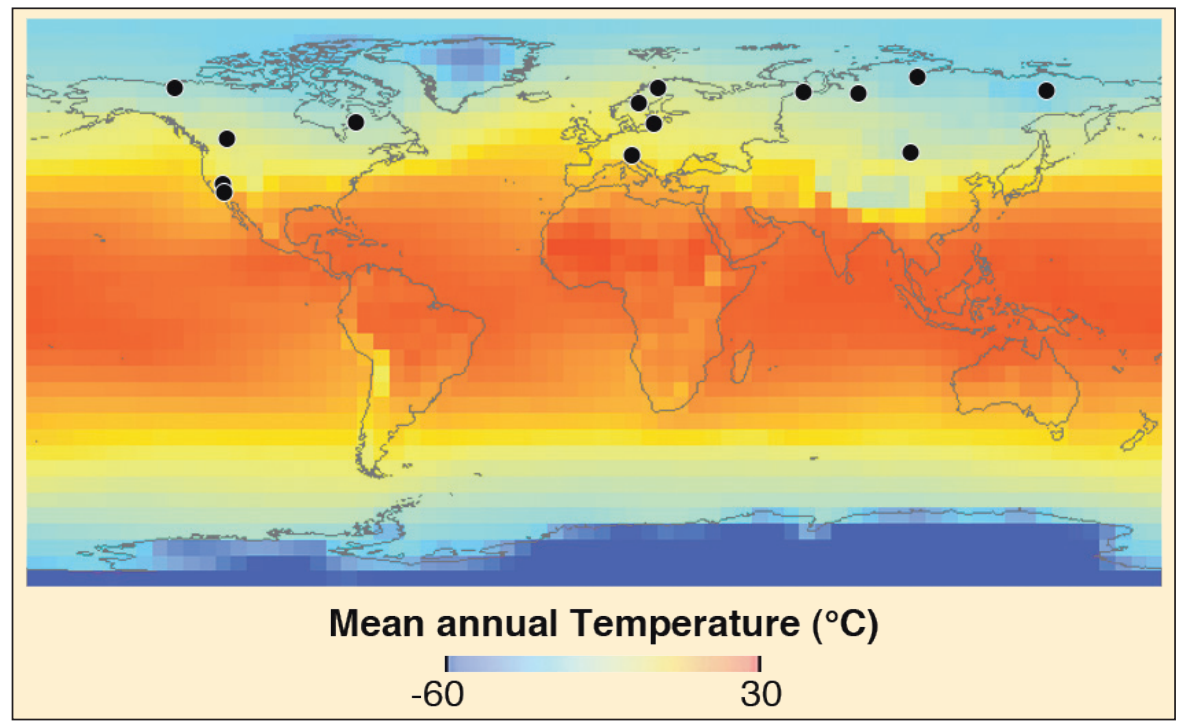

Figure 1: Map showing the location of the 14 simulated extratropical tree-ring-chronology sites (black dots) in the Northern Hemisphere that were used in Theme 1 for the reconstruction of Northern Hemisphere temperature with strongly limited proxy data set. Underlying colors represent average annual temperatures (1961-1990). Figure by W. GOSS, NOAA-NCDC Paleoclimatology/WDC for Paleoclimatology).

This theme focuses on the capacity of a less limited set of proxy-data sites to enable reconstruction of hemispheric (again defined as $20-90^{\circ} \mathrm{N}$ ) mean annual temperature and spatial temperature patterns. The pseudo-proxy data set consists of 66 tree-ring sites in the Northern Hemisphere at $>40^{\circ} \mathrm{N}$ and is designed to mimic the dataset used by D'Arrigo et al. (2006).

\section{Theme 3: Reconstruction of Northern} Hemisphere temperature and global spatial patterns using a relatively rich proxy data set (to be implemented)

This theme focuses on the capacity of a richer and more spatially diverse set of proxy data sites to enable reconstruction of hemispheric (here defined as $0-90^{\circ} \mathrm{N}$ ) mean annual temperature and global spatial temperature patterns. The pseudoproxy data set contains 104 sites from different archives spread across the globe. It is designed to mimic the dataset used by Mann et al. (1998) and in numerous reconstruction simulation experiments (e.g., Mann et al., 2007; Smerdon et al., 2010).

The above three themes are designed to explore how proxy richness and spatial extent affect reconstruction fidelity of the Northern Hemisphere mean temperature (Themes 1-3), and of spatial temperature patterns in the Northern Hemisphere (Theme 2 ) and globally (Theme 3 ).

Theme 4: Reconstruction of spatial drought patterns (currently in development)

This theme is still under development; it will be based on a pseudo-proxy dataset designed to mimic that used in the North American Drought Atlas (NADA; cf., Cook et al., 2004). A timetable for implementation is being developed.
The Paleoclimatology Branch of NOAA's National Climatic Data Center/World Data Center for Paleoclimatology is providing the simulated proxy and instrumental data sets of the PR-Challenge and is also archiving the contributed reconstructions so that they can be cross-compared: www. ncdc.noaa.gov/paleo/pubs/pr-challenge/ pr-challenge.html.

The PR-Challenge implementation team consists of Nicholas Graham, Rosanne D'Arrigo, Kevin Anchukaitis, Eugene Wahl, and David Anderson. We gratefully acknowledge Edward Cook for valuable ideas and encouragement, and Caspar Ammann for his inception of the PR Challenge project. Tree-ring pseudoproxy formulation used the "VS-Lite" tree growth model developed by Suz Tolwinski-Ward and collaborators (Tolwinski-Ward et al., 2010).

The PR-Challenge is sponsored by NOAA's Office of Oceanic and Atmospheric Research/Climate Program Office (Climate Change Data and Detection Program, grant NA08OAR4310732) and the PAGES/CLIVAR Intersection.

\section{References}

Amman, C., 2008: The Paleoclimate Reconstruction Challenge, PAGES news, 16(1): 4.

D'Arrigo, R., Wilson, R. and Jacoby G., 2006: On the long-term context for late 20th century warming, Journal of Geophysical Research, 111: doi:10.1029/2005JD006352.

Esper, J., Cook, E.R., and Schweingruber, F.H., 2002: Low-frequency signals in long tree-ring chronologies for reconstructing of past temperature variability, Science, 295: 2250-2253.

Mann, M.E., Bradley, R.S. and Hughes, M.K., 1998: Global-scale temperature patterns and climate forcing over the past six centuries, Nature, 392: 779-787.

Tolwinski-Ward, S.E., Evans, M.N., Hughes, M.K. and Anchukaitis, K.J., 2010: An efficient forward model of the climate controls on interannual variation in tree-ring width, Climate Dynamics, doi:10.1007/s00382-010-0945-5.

For full references please consult:

http://www.pages-igbp.org/products/newsletters/ref2011_2.pdf

\section{PAGES Calendar 2010/2011}

(3) $4^{\text {th }}$ PALSEA Workshop: Ice sheet modelingconsistency with RSL, ice-sheet extent and climate data, GIA and GCM modeling 24 - 26 Aug 2011 - Boston, USA http://www.pages-igbp.org/calendar/upcoming

\section{(3) Developing new techniques and core locations to constrain the history of the Greenland Ice Sheet 20 Oct 2011 - Corvallis, USA \\ http://www.pages-igbp.org/calendar/upcoming}

\section{(2) Processes and Quaternary history of dust dynamics: Low-latitude records and global implications}

31 Oct - 03 Nov 2011 - Bremen, Germany

http://www.pages-igbp.org/calendar/upcoming
(3) Continental drilling in the East African Rift: Strategic planning workshop 14 - 16 Nov 2011 - Providence, USA

http://www.pages-igbp.org/calendar/upcoming

\section{$3^{\text {rd }}$ PAGES Varves Working Group workshop} 21 - 23 Mar 2012 - Manderscheid, German http://www.pages-igbp.org/workinggroups/varves-wg

\section{(2) $4^{\text {th }}$ PIGS workshop - Past Interglacials: Forcing and response 2 - 5 Jul 2012 - Cambridge, UK http://www.pages-igbp.org/calendar/upcoming}

